\title{
Two Types of Argument from Position to Know
}

\section{DAVID BOTTING}

\author{
Independent Researcher \\ Flat 1, 38 Westfield Rd., \\ Yeovil, Somerset, BA21 3DA \\ U.K. \\ davidbotting33@yahoo.co.uk
}

\begin{abstract}
In this paper I will argue that there is an inductive and a noninductive argument from position to know and will characterise the latter as an argument from (epistemic) authority because of providing content-independent reasons. I will also argue that both types of argument should be doubt-preserving: testimony cannot justify a stronger cognitive attitude in the arguer than the expert herself expresses when she testifies. Failure to appreciate this point undercuts Mizrahi's (2013b) claim that arguments from expert opinion are weak.
\end{abstract}

Résumé: Dans cet article je soutiendrai qu'il existe un argument inductif et non inductif de la position du savoir et que l'argument non inductif sera qualifié d'argument d'autorité (épistémique) à cause de ses raisons dépourvues de contenu relié à leur conclusion. Je soutiendrai également que les deux types d'arguments devraient préserver le doute: le témoignage de l'expert ne peut pas justifier une attitude cognitive plus forte chez la personne qui fait appel à l'expert que chez l'expert lui-même. $\mathrm{Ne}$ pas comprendre ce point compromet l'affirmation de Mizrahi (2013b) que les arguments fondés sur l'opinion des experts sont faibles.

Keywords: expertise, authority, testimony, argument from position to know, argument from expert opinion

\section{Introduction}

There has been much discussion in recent issues of Informal Logic about the strength of appeals to expert opinion since Mizrahi (2013b) made a surprising, intriguing and (on its face) strong case that arguments from expert opinion are weak and provide only weak reasons. He summarizes his argument as follows (2013b, pp. 58-59):

(C) David Botting. Informal Logic, Vol. 38, No. 4 (2018), pp. 502-530. 
(1) Arguments from expert opinion are weak arguments unless the fact that expert $E$ says that $p$ makes it significantly more likely that $p$ is true.

(2) [As empirical evidence on expertise shows] the fact that $E$ says that $p$ does not make it significantly more likely that $p$ is true.

(3) Therefore, arguments from expert opinion are weak arguments.

On the face of it the vulnerable premise is (2), where it may be questioned whether it is: i) true, and; ii) self-undermining since the argument might appear to illegitimately make an exception for expert opinion about expertise while endorsing skepticism about expertise of all other kinds. This has been the main focus of attack and defence so far (Seidel 2014; Hinton 2015; Mizrahi 2016; Seidel 2016). ${ }^{1}$ I will argue that the problematic premise is actually (1), which, as it stands, is under-described; Mizrahi is tacitly taking "weak arguments" to be those that do not justify belief for one appealing to expert opinion, where instead weak arguments should be those that do not justify the arguer's holding whatever cognitive attitude is expressed in the opinion. In other words, it matters how exactly $E$ says that $p$, and the empirical evidence in (2) only has to show that $p$ is likely enough with respect to the cognitive attitude expressed by $E$ 's saying that $p$ in the way $E$ says it.

In short, if an expert only makes a tentative assertion, then it should be no surprise that it does not justify belief for the arguer appealing to it - the proper question is whether it justifies the arguer's holding something tentatively to be true, and if it does, it is a strong argument and provides strong reasons for that attitude. I call this doubt-preservation and will argue that most of Mizrahi's empirical evidence ignores this feature. Unfortunately, it is equally ignored by Seidel and Hinton when they wrongly take Mizrahi to be talking exclusively about predictions in conditions of uncertainty, which would be clear cases where the expert would not take herself to be expressing outright belief in what she says or to be providing strong reasons for outright belief, and appeal to the expert will provide the arguer with reasons for outright belief just

\footnotetext{
${ }^{1}$ Outside of the pages of Informal Logic, Walton (2014) offers some briefer comments.
}

(C) David Botting. Informal Logic, Vol. 38, No. 4 (2018), pp. 502-530. 
as weak. The expert's opinion may nonetheless provide strong reasons for the arguer to hold the weaker attitude that the expert is expressing in giving her opinion. The way Seidel and Hinton interpret Mizrahi's examples (i.e., as predictions) effectively makes all such appeals weak by definition and not worth arguing about if taken as justifications for outright belief. Thus, I will argue that Seidel and Hinton's diagnosis of what is wrong about Mizrahi's argument is equally wrong and give what I believe to be the right diagnosis in terms of doubt-preservation. When we come to consider Mizrahi's examples, I will show that in most cases, contrary to appearances and to what Mizrahi, Seidel, and Hinton all say, they are strong arguments, albeit for weaker attitudes than belief. By choosing the correct attitude, Mizrahi's premise (2) will turn out to be false, as is his conclusion: arguments from expert opinion are strong arguments, or at least they can be.

In the few examples where, arguably, Mizrahi does consider experts' making strong, confident assertions that would justify outright belief, Mizrahi seems strangely ambivalent about whether belief is justified, as I will show; in fact, Mizrahi's view seems to be that belief $i s$ justified, but that the argument is no longer a simple argument from expert opinion. I largely agree with Mizrahi on the terminological issue here, but taking this to lead to skepticism about expert opinion amounts almost to winning the debate by stipulation: if those he is attacking take argument from expert opinion to be just these kinds of arguments, then Mizrahi is committed to the view that these arguments are strong after all and his criticism then becomes the much less skeptical one that these arguments are badly named. I will argue that "argument from expert opinion" and "argument from position to know" does, in fact, conceal an ambiguity and that the stipulation Mizrahi makes is, although insufficient to settle the debate, well-motivated. Why does Mizrahi state that these are not really arguments from expert opinion? What, exactly, does Mizrahi take arguments from expert opinion to be?

Although he does not use the term, Mizrahi expresses the kind of reason that he is talking about (and saying to be weak) as a content-independent reason. Mizrahi's way of putting it is to say 
that when there is such a reason it is a reason to accept $p$ just because expert $E$ says so. Hence:

Expert: It is better to invest in real-estate than in bonds.

Non-expert: Why?

Expert: Because Expert $E$ says so, that's why!

is given more or less stipulatively as an example of the kind of thing Mizrahi means when he talks about appeal to expert opinion (Mizrahi 2013b, p. 60). This is taken as having no suppressed premises. If further premises are added, then it is simply a different kind of argument. ${ }^{2}$

It is characteristic of authorities that they are reason-giving and that at least one of the reasons they give is content-independent. For example, in Divine Command Theory you ought to do what God commands for the reason that He commands it, irrespective of what the command is. Similar things are often held for the law, where the sole fact that the law has commanded something (irrespective of what it is and whether you agree with it or not) is at least one reason for you to do it. These are examples of deontic

\footnotetext{
${ }^{2}$ I think that this is the thrust of Walton's (2014, p. 142) complaint that Mizrahi "refuses to countenance the possibility that other premises of the form of the argument from expert opinion need to be taken into account". Responding, Mizrahi (2017, pp.1-2) says that all formulations of the argument require something like premise (1), but I think that in saying this Mizrahi has mistaken the nature of Walton's criticism, erroneously seeming to think that Walton is talking about other formulations of the argument where in fact Walton is talking about other premises. These premises relate to the critical questions that Walton associates with the argumentation scheme. Some critical questions, as we will see, amount to no more than asking whether the premises are true, and although they elicit subordinate argumentation (for the truth of the premises) this argumentation is not a part of the original argument. Other critical questions elicit further premises that were suppressed in the original argument and are needed for the argument to be a good one. These are the ones that Mizrahi's way of defining appeal to expert opinion effectively rules out; when these are brought in, Mizrahi will say that it is not an argument from expert opinion any more. Up to a point I agree, since I do not believe that the expert opinion as such is doing any real work any longer.
}

(C) David Botting. Informal Logic, Vol. 38, No. 4 (2018), pp. 502-530. 
authority. ${ }^{3}$ Similarly for epistemic authorities, the fact that an authority has told you that something is so is in and of itself a reason to believe that it is so and generally justifies believing that it is so.

By virtue of their expertise in a domain, experts are presumed to be epistemic authorities in their domain. With regard to truths that do not belong to a specific domain and are generally accessible, an ordinary person might be an epistemic authority. There is nothing special then about experts as such, and sometimes I will talk about arguments from expert opinion and arguments from position to know interchangeably. When Mizrahi talks about argument from expert opinion, he is really talking about a kind of argument from epistemic authority. The mere fact that an epistemic authority has said something is an epistemic reason to believe it and, other things being equal, justifies believing it, in which case this particular instance of the argument from epistemic authority is "strong" or "valid."

If an argument from position to know is an argument from epistemic authority, then I agree with Mizrahi that this is how it ought to be defined. The addition of further premises makes it no longer an argument from epistemic authority because it is not only the expert's saying so but further facts that together provide a reason to believe (whether strongly or weakly) that what the expert says is true. It also means that Walton's argumentation schemes for argument from expert opinion/position to know (to be examined in a moment), since they do involve something like suppressed premises (in the form of critical questions that need to be answered for the argument to be considered good), are not an argument from position to know as Mizrahi defines it.

The problem is that this makes the debate over Mizrahi's more surprising skeptical claims rest in the end on an equivocation over how an argument from position to know is defined. The possibility is opened up that there are arguments where expert opinion is appealed to that are strong, but these are not arguments from expert

\footnotetext{
${ }^{3}$ In common with Mizrahi (2013b) I will not discuss deontic authority here, although roughly the same analysis will apply to deontic authorities as to epistemic authorities.
}

(C) David Botting. Informal Logic, Vol. 38, No. 4 (2018), pp. 502-530. 
opinion as Mizrahi uses the term because it is not only because the expert has said something that gives us a reason to believe it, but because of further facts that should be expressed in the premises. Such further facts might be, for instance, the fact that experts agree (Mizrahi 2013b, p. 61), or the fact that the expert is verifiably reliable, as I will argue later. I think that Mizrahi is right about this and that he has stumbled almost inadvertently over two quite different kinds of argument, both of which appeal to expert opinion.

However, this results in him succeeding in what he wants to prove almost by stipulation. He appeals to some empirical results that seem to show that experts are not that much better than a coin toss at getting things right [premise (2) above]. However, it seems to be open that at least sometimes this is not the case, and we can imagine two different kinds of evidence that might be given for the expert's providing a strong reason in such a case: the evidence the expert uses in reaching her conclusion, or evidence that the expert is usually right and for that reason probably right in this case too. It will turn out that evidence of the first kind would be given as an answer to the Backup Evidence Critical Question and that evidence of the second kind would be given as an answer to the Trustworthiness Critical Question. By including these critical questions, Walton is thereby committed to having such evidence and would not mind including it as part of what makes an instance of the argumentation scheme strong. In short, he would not accept the stipulation by which such arguments are not really arguments from expert opinion, in which case, even if Mizrahi is right, his criticism is now the much weaker one "You shouldn't call it an argument from expert opinion!"

Considering the first kind of evidence (i.e., the evidence on which the expert's statement was based in the first place) Mizrahi (2013b, p. 71) says:

If $E$ 's assertion that $p$ is based on evidence, then we would accept $p$ not just because $\mathrm{E}$ says that $p$ but because $E$ says that $p$ and $p$ is based on evidence. (We can appeal to the evidence directly and cut the middleman. ..)

Now it is the evidence doing all the work, and we are no longer accepting A just because E said it. In fact, E is only the means of 
getting access to the evidence and E's say-so is not in itself being used as evidence for its truth. The problem for Mizrahi now is that those he is arguing against may very well accept this because, in what they mean by argument from expert opinion they need not accept this just because requirement. ${ }^{4}$ If so, then Mizrahi is talking past those he seeks to argue against.

I will be focussing more on the second kind of evidence (i.e., the expert's reliability). When the arguer is able to provide evidence of the expert's reliability, the argument effectively changes from being an argument from expert opinion since now, once again, we are no longer accepting $p$ just because $E$ said it but because $E$ said it and $E$ is reliable. Here, $E$ 's say-so is in itself being used as evidence for $p$ 's truth, but not on its own. This need not be a weak

${ }^{4}$ Following on from footnote 2, this evidence constitutes the premises that Walton says that Mizrahi "refuses to countenance". As mentioned above, Walton seems committed to such evidence being provided in order for the argument from expert opinion to be strong, but this probably would not bother him. There is a complication here which I choose to ignore, namely whether the evidence (since it is now said to be the evidence rather than the testimony that is playing the justificatory role) is such that the arguer is actually competent to evaluate it. I am not terribly concerned about this novice/expert problem: how are novices to recognize experts or evaluate the evidence that the experts evaluate? But in fact all that the arguer needs is the justified belief that there is such evidence for the given claim - that is to say, that $p$ is based on evidence without necessarily knowing what the evidence is - and this is justified if, as we will see later, we are justified in believing that the expert (who we are putatively treating as a "middle-man") is acting professionally in compiling the evidence. Professional trust is something that even novices should have no trouble in recognizing.

It is not entirely clear which of these Mizrahi is proposing: that the evidence itself provide strong reasons (as suggested by the "cut out the middle-man" comment) or that the expert's opinion being based on evidence (as suggested by "because ... and $p$ is based on evidence", which does not seem to require knowing what the evidence is) provide strong reasons. I suggest that he ought to mean the second of these, and that justified belief that the expert's opinion is based on evidence is what we have when we have professional trust in the expert. Mizrahi is not then saddled with the view that it is the non-expert's evaluation of the expert's evidence itself that justifies (or not) his belief that $p$. 
argument. I will show, perhaps surprisingly, that it is an argument in which expertise is similarly incidental.

Mizrahi has, I think, correctly identified a particular kind of argument, and perhaps this particular argument is what we should take the argument from expert opinion to be, ${ }^{5}$ but he is wrong to identify this as the target of his objections. A more neutral way of putting the matter is that there are two types of argument from expert opinion or position to know. I will call these types "noninductive" and "inductive." The non-inductive type is an argument from epistemic authority, and I will explain later how I think this argument works and show that it is not necessarily weak. The "inductive" type is so named because I think it reduces to an inductive argument from reliability in which it just so happens that the reliability in question concerns testimony. It is this that I will explain first.

\section{The inductive argument from position to know}

The basic argument from position to know, of which argument from expert opinion is a sub-type, is given by Walton, Reed, and Macagno (2008, p. 13) as the following argumentation scheme:

Major Premise: Source $E$ is in a position to know about things in a certain subject domain $S$ containing proposition $p$.

Minor Premise: $E$ asserts that $p$ (in domain $S$ ) is true (false). ${ }^{6}$

5 Thus,

once we take into account considerations of evidence for $p$ and whether or not $p$ is consistent with common knowledge in a field, then an argument from expert opinion is no longer just an appeal to expert opinion. Rather, it is an appeal to expertise, evidence, and agreement among experts. In that case, however, why call such an argument "appeal to expert opinion"? (Mizrahi 2013, p. 71)

I sympathize with Mizrahi here and believe that only Mizrahi's kind of argument is genuinely an appeal to epistemic authority; nonetheless, if the fact is that such arguments are called appeals to expert opinion, it is with these types of arguments that Mizrahi has to deal with if he wants to show that appeals to expert opinion are weak arguments, since otherwise he is succeeding by stipulation.

${ }^{6}$ I have changed the symbols slightly from the original text so that it is consistent with my use of $E$ to signify the expert and $p$ to signify the proposition expressed

(C) David Botting. Informal Logic, Vol. 38, No. 4 (2018), pp. 502-530. 
Conclusion: $p$ is true (false).

Matching the argument from position to know ... are the following three critical questions.

CQ1: Is $E$ in a position to know whether $p$ is true (false)?

$\mathrm{CQ} 2$ : Is $\mathrm{E}$ an honest (trustworthy, reliable) source?

CQ3: Did $E$ assert that $p$ is true (false)?

Note that CQ1 amounts only to asking, "Is the major premise true?" and CQ3 amounts only to asking: "Is the minor premise true?" for which reason, answering these questions does not involve adding premises but only providing subordinate argumentation for the truth of the premises. It is CQ2 - called by the authors the Trustworthiness Question - that is the significant one. Answering this question does provide further information that needs to be added into the argument as premises and affects the strength of the argument.

The intuition underlying the Trustworthiness Question is that we only take testimony to justify our belief when we think that the testifier is at least attempting to say something true and succeeds in doing this a respectable percentage of the time. ${ }^{7}$ However, it should

in the opinion. Note that I would object that the minor premise is too strongly stated as asserting that $p$ is true-this makes it seem as if only outright belief were good enough. Note also that accepting this kind of strong assertion as the requirement effectively means that whenever an expert's opinion is not asserted in this strong way, this argumentation scheme simply does not apply to it. Thus, strictly speaking, many of the examples that Mizrahi will give will turn out not to be genuine instances of this argumentation scheme, because I will argue that in those examples the experts are not making these kinds of assertions put only advancing claims more tentatively.

${ }^{7}$ Walton seems to prefer the language of defeasibility and thinks that Mizrahi's basic problem is in failing to note that the inference is a defeasible one (Walton 2014, p.148). I think that this is a red herring: whether we use the language of defeasibility or probability, I do not see how Walton can deny the requirement for an expert's saying something (in their domain) to indicate that what is said is significantly more likely to be true than not [Mizrahi's premise (1)], and the Trustworthiness Question seems to trade on this kind of likelihood whether he uses the term or not.

Of course, not all propositions are alike, and we do not take a layman to be succeeding in saying something true when the propositions he is expressing

(C) David Botting. Informal Logic, Vol. 38, No. 4 (2018), pp. 502-530. 
be noted that there is something odd about asking the Trustworthiness Question: if we are in some doubt about a testifier's trustworthiness, her answering the question with "Yes, I am trustworthy" is not going to help. True, it is the arguer appealing to the testimony, and not the testifier, to whom the critical question is addressed and who has to meet the burden of proof. There seems to be three ways in which the burden may be met: (i) inductive evidence of the reliability of the testifier is provided; (ii) the evidence which the testifier used in reaching her belief that $p$ is provided; (iii) she is endorsed in some way by other sources, that is to say, by further testimony. Obviously, (iii) must eventually be grounded in (i) or (ii) and can be left out of further discussion.

Mizrahi has already considered (ii) under the guise of the Backup Evidence Question, which is a critical question in the argumentation scheme of argument from expert opinion but does not occur in the more basic argument from position to know. He also says that if we have the evidence for $p$, then we will be justified in believing $p$ on the basis of this evidence (or, more carefully, on the basis that the expert's opinion was based on evidence, whatever that may be) any reference to expert opinion or testimony falling out of the account. I think this is mostly true. Note, though, that conceding this does not mean that there is not a content-independent reason to be taken account of as well. But if the evidence is already sufficient for the testifier to believe it, it

belong to a specialized domain. In these cases, the testifier needs certain credentials before we can take her to be trustworthy, hence the need for "experts".

An anonymous reviewer challenges me [and by implication Mizrahi's premise (1)] on this point, claiming that it presupposes a veritistic analysis of expertise, rightly pointing out that Seidel (2014, pp. 196-98) rejects this analysis. But I am not here proposing any analysis of expertise at all but only saying why we take testimony to be a mark of truth when we do so take it. It is a point about justification by testimony rather than a point about expertise. For our purposes, an expert is simply one such that appealing to their opinion gives you reasons to think that what they say is true, and I fail to see how this belief can be justified if Mizrahi's premise (1) is false. Of course, this implies that when the argument from expert opinion is weak it would be just another way of saying that the 'expert' appealed to was not, in this instance at least, an expert.

(C) David Botting. Informal Logic, Vol. 38, No. 4 (2018), pp. 502-530. 


\section{Botting}

should be sufficient for the arguer as well; the addition of a further reason will not make any significant difference.

It remains to consider (i). We are justified in believing $p$ on the basis of E's testimony to the extent that we are justified in believing $E$ 's testimony to be reliable, and we are justified in this to the extent that we can independently verify the truth of what $E$ says. In other words, we establish her track-record of speaking truths over falsehoods and are justified in believing $p$ insofar as the truths preponderate over the falsehoods. ${ }^{8}$ If it is high enough, then the burden of proof imposed by the Trustworthiness Question can be met, and we are justified in believing $E$ to be: i) not biased, ii) honest and; iii) conscientious ${ }^{9}$ (Walton, Reed, and Macagno 2008, p. 31).

However, how much work is actually being done by these ethotic considerations in this case? Let us suppose that although the arguer would be justified in believing that $E$ is not biased and is honest and conscientious, as a matter of fact, the arguer does not believe these things to be true of $E$. Let us go further and suppose that the arguer takes $E$ to be an inveterate liar, that is to say, $E$ is not even attempting to say true things but is in fact attempting to say false things. Still, the arguer has empirical evidence that, liar or not, $E$ rarely if ever says anything false. It seems to me that the argument goes through in the same way as before and is a perfectly respectable inductive argument which just happens to mention testimony but would not be significantly different if, instead, it mentioned the readings of a barometer. Now, you could say that the barometer in some sense is responding to reasons and in some causal sense has reasons for producing the outputs that it does, and this is not true of the liar. But I think that we would attribute the same to the liar: in spite of herself, she instantiates some reliable causal mechanism for producing truth.

My conclusion is that the inductive argument from position to know reduces to an ordinary inductive argument in which features

\footnotetext{
${ }^{8}$ This, of course, is basically Hume's way of doing things. I brush under the carpet all the reference class problems here.

${ }^{9}$ These correspond to the sub-questions of the Trustworthiness Question.

(C) David Botting. Informal Logic, Vol. 38, No. 4 (2018), pp. 502-530.
} 
that are specific to testimony and authority (specifically, the ethos of the 'expert') are irrelevant.

This does not, however, mean that instances of such arguments are weak arguments. In order to show that such arguments are weak Mizrahi needs to show that our assumption that such reports of high reliability are forthcoming is just not true in the case of expertise; as a matter of fact, experts are just not as reliable as barometers, and that is all there is to it. It is not impossible in principle for an argument from expert opinion to be strong; it is just a matter of fact that none (or very few) actually are.

Mizrahi gives several examples:

a) The economic example: the claim made by the FBI about how much money U.S. businesses lose annually to counterfeiting (Mizrahi 2013b, p. 62).

b) The scientific example: the claim made by Fleischmann and Ponsto have discovered a way to bring about cold fusion (Mizrahi 2013b, p. 62).

c) The prediction example: [citing Tetlock (2005)] experts in several different fields were found to be not that much more reliable at predicting than "dart-throwing chimpanzees" (Mirahi 2013b, p. 64).

d) The medical/economic example: most papers published in medical and economic journals have turned out to be false within a few years. (Mizrahi 2013b, p. 62)

e) The doctor example: a doctor's diagnosis has a 1 in 12 chance of being dangerously wrong (Mizrahi 2013b, p. 62).

f) The accountancy example: tax returns made by professionals are less likely to be accurate than those made by nonprofessionals (Mizrahi 2013b, p. 62).

g) The psychologist example: non-experts succeed as well as experts in providing therapy (Mizrahi 2013b, p. 62).

Mizrahi (2013b, pp. 62-63) concludes:

Since the research on expertise shows that experts are only slightly more accurate than chance . . . it supports the second premise ... which is that the fact that $E$ says that $p$ does not make it significant- 


\section{Botting}

ly more likely that $p$ is true. Together with the first premise . . which says that arguments from expert opinion are weak arguments unless the fact that $E$ says that $p$ makes it significantly more likely that $p$ is true, it follows that arguments from expert opinion are weak arguments. In support of the first premise, consider the following: Would you trust a watch that gets the time right $55 \%$ of the time? Would you trust a thermometer that gets the temperature right $55 \%$ of the time? I suspect the answer to these questions is "no." Similarly, a method of reasoning, such as appealing to expert opinion, is trustworthy only if expert opinion is significantly more likely to be true. Since, as the research on expertise shows, the fact that an expert asserts $p$ does not make it significantly more likely that $p$ is true, appealing to expert opinion doesn't seem like a trustworthy method of reasoning.

If valid, this is a surprising, even shocking conclusion. We put our faith in experts all the time, yet if Mizrahi is right, then we are wrong to do so. Experts, it seems, still have a role to play: they can point us to the evidence, or, as long as we suppose them to be professionals, they can reassure us that such evidence exists. The evidence itself, Mizrahi says later, may give us strong reasons and justify our believing the claim they support, but the expert opinion itself only gives us weak reasons.

This latter point about professionalism is relevant to Seidel's "argument 5" (2014, pp. 210-16) objection that Mizrahi's argument is self-undermining because it itself depends on expert opinion. I will take a brief detour to discuss this objection because it is a general argument which, if valid, makes any discussion of the empirical claims redundant. Seidel (2014, p. 213) attributes to Mizrahi the following fallacious argument:

(1) Evidence gained by scientific and empirical research suggests that reference to expert opinion is not reliable.

(2) Scientific and empirical research is a reliable method.

(3) As a matter of fact, the evidence gained by scientific and empirical research that suggests that reference to expert opinion is not reliable is evidence gained by assuming the reliability of reference to expert opinion.

Therefore, 
(4) There is evidence that suggests that reference to expert opinion is not reliable.

Therefore,

(5) Reference to expert opinion is not reliable.

It is inaccurate to attribute this argument to Mizrahi and then say that it is fallacious. Rather, I think that what Seidel is trying to say is this: our evidence that (1) is true must come either by conducting the scientific and empirical research ourselves or from experts. Mizrahi concedes that the empirical evidence he advances in support of his premise is not evidence that he has gained by conducting it himself but, as it says in (3), "gained by assuming the reliability of reference to expert opinion." Therefore, Seidel concludes, Mizrahi is simply taking the expert's word for it that there is any such evidence (Seidel 2014, p. 213). I think that Mizrahi (2016) misses the point when, in response to this objection, he claims that he is appealing to the experiment itself, or to decision procedures, in order to provide the justification for his premise. Granted, premise (2) in Mizrahi's argument begins with "[As empirical evidence on expertise shows] ..." and not "[According to experts on expertise] ..." And Mizrahi is right that appealing to an expert's evidence is a different argument from appealing to their opinion. Formally speaking, there is no contradiction here. But there is an epistemic contradiction, since there is no reason to suppose that there is any such experiment or decision procedure in the first place except for the fact that the expert expresses an opinion on their basis. Although premise (2) refers to empirical evidence, we are taking it on the expert's say-so that this premise is true and that this evidence exists. It is only acceptable to refer to an experiment for one's justification if one is justified in believing there to be such an experiment. Mizrahi's reasoning is, then, self-undermining, because there is no reason for believing there to be such an experiment if experts are as unreliable as Mizrahi says. ${ }^{10}$

\footnotetext{
${ }^{10}$ An anonymous reviewer claims that the issue here is one of pragmatic selfcontradiction. I don't see this (and I doubt that Seidel sees it this way either, though the text does not rule it out). Let us suppose that as a matter of fact my methods of gathering evidence were severely defective. Even so, I would still

(C) David Botting. Informal Logic, Vol. 38, No. 4 (2018), pp. 502-530.
} 


\section{Botting}

However, Mizrahi goes on to give what I think is the correct answer to this problem: he concedes that he is relying on the word of experts that there is such evidence, but that he is not relying on their epistemic reliability but relying only on their professionalism. It is, in Mizrahi's view, acceptable to have professional trust in experts, but not epistemic trust. Finishing, Mizrahi (2016) says:

All that I need to assume is that the scientists who conducted the
studies on expert performance are professionals, i.e., they can be
trusted to follow procedures (e.g., protocols of randomization,
blinding, and the like), not that they are experts whose judgments
are to be believed or accepted. In other words I accept the results of
experimental studies on expert performance because they are the
results of properly conducted experiments, not because they are as-
serted or reported by experts.

This defence, however, seems fragile. Granted, appeal to an expert's evidence is different from appeal to the expert's opinion. It is also true that this avoids any formal kind of contradiction. However, even if we concede that the expert may be just a 'middleman' who can be cut out, this in itself does not show that such a middleman is unjustified or that we would be unjustified in appealing to his opinion. Also, any empirical evidence that an expert's opinion is unreliable will show equally that the expert's methods are unreliable. On the assumption that the expert acted professionally and based her opinion on evidence, then in cases where arguing from expert opinion is weak, appealing to the expert's evidence will be equally weak, and in cases where appealing to the expert's evidence is strong, appealing to the expert's opinion should also be strong. Mizrahi seems to be committed to situations where the nonexpert is more justified by the evidence than the expert herself is and where the arguer can be justified by the expert's evidence but would not be justified by the expert's testimony, despite the fact

have that evidence, and that evidence would be evidence for whatever it is evidence for, including, possibly, that my methods are defective. I do not see there to be any pragmatic contradiction in saying that I have evidence $D$ and saying (on the basis of $D$ ) that my method $M$ of gathering evidence $D$ is defective - this says something true! What is, however, true, is that I am not justified in believing $D$ in this situation, even though it is ex hypothesi true.

(C) David Botting. Informal Logic, Vol. 38, No. 4 (2018), pp. 502-530. 
that the expert reasons from the evidence in a way that is at least equal to that of the non-expert and probably better. In short, he seems to suppose that there can be a situation where the nonexpert's track record is better than the expert's. Mizrahi does not, I think, want to say that all of the experts shown to be unreliable were not professional. But then, even Fleischmann and Pons conducted experiments and based their claims on evidence, or so we might suppose. They may have conducted themselves professionally. So, Mizrahi seems committed to saying that appeal to their authority is valid so long as they are able to refer to experiments that they carried out or the evidence from those experiments. The expert then has a simple way to change a weak reason into a strong one, and Mizrahi seems able to object to this manoeuvre only on the grounds that it is not really an argument from expert opinion anymore.

But perhaps Mizrahi would say that appeal to Fleischmann and Pons's authority is not valid even in this case. After all, their evidence and procedures led them to make a claim that was false, and if Mizrahi is right, this is not an isolated incident but the norm. But then it seems inconsistent for Mizrahi to say that we can rely on evidence and procedures. If evidence and procedures do not serve experts very well, why should they serve those who appeal to that evidence any better? Why would we be justified in believing on the basis of the evidence if the experts are not? I do not quite see how being justified on the basis of evidence and being justified on the basis of testimony (based on that evidence) can come apart in the way Mizrahi seems to suppose here. And what makes the evidence and procedures of the experts on expertise better than the evidence and procedures of the experts they are studying? Why should we believe what experts on expertise say? Why should we place any faith in evidence and procedures at all, if they lead both experts and non-experts who rely on the evidence astray so often? Why should we take scientific and empirical research to be a reliable method? Thus, I think that Mizrahi's account does face a problem of selfundermining that can only be solved by him stipulatively by saying that when you appeal to evidence, it is not really a genuine appeal 
to expert opinion anymore, but then he is talking past those who he seeks to argue against.

That is the end of the detour.

I would like to divide Mizrahi's examples into three groups because I think that there are relevant differences between them. These groups are:

GROUP 1: (f), (g)

GROUP 2: (a)

GROUP 3: (b), (c), (d), (e)

Group 1 consists of the accountancy (f) and psychologist (g) examples. Note that these are anomalous: Mizrahi claims to be giving examples where expert opinion was only slightly better than chance, but in these examples expert opinion is said to be not much better than (and roughly equal to) non-expert opinion. However, if one of these is considerably better than chance, then so will the other, and appeal to either expert or non-expert opinion may be a strong argument. In other words, these arguments show that the argument from expert opinion is weak only if we believe that appeal to non-experts, or appeal to our own abilities to carry out the cognitive tasks involved, is similarly weak and do not justify the beliefs we form thereby. If we believe that we have carried out these tasks well enough to be justified in believing that we have arrived at the correct result, we would also be justified in believing that an expert has arrived at the correct result supposing only that they have the same basic ability to carry out these tasks. We do not need to suppose that the expert has special knowledge or special skills that we do not in order for the expert's opinion to be sufficient for us to be justified in believing what the expert says. Maybe we would be equally justified by doing the cognitive work ourselves as we would be by relying on the expert—what of it? Being not much better (or even worse) than non-expert opinion does not equate with being not much better than chance, and it is the latter 
that is important by Mizrahi's own lights. This group does not prove what Mizrahi wants. ${ }^{11}$

Group 2 consists of the economic (a) example. The FBI seems to be fairly confident in its claim about how much money businesses would lose through counterfeiting. Mizrahi (2013b, p. 63) reasons:

the article goes on to say that the FBI has no record of source data or methodology for generating the estimate [which] cannot be corroborated." This makes it clear that accepting the claim that U.S. businesses lose $\$ 200-\$ 250$ billion to counterfeiting on an annual basis solely on the ground that the FBI says so would be to accept a claim on a rather shaky ground, for the FBI's estimate could very easily be off, given the fact that it "cannot be corroborated."

This is true, but it only expresses the truism that we are not justified in believing what someone says when we also believe that they have no evidence or reasons for the truth of what they say. However confident they seem, we take them to be doing little more than guessing. The 'expert' cannot even be assumed to acting professionally in this example. ${ }^{12}$ This group does not prove what Mizrahi wants either.

The interesting cases are in Group 3, where experts can be assumed to be acting professionally, and following procedures that are at least as stringent as those followed by the experts on exper-

\footnotetext{
${ }^{11}$ It follows that Seidel and Hinton, who focus quite heavily on this point, could have saved themselves the trouble: even if experts are not better than nonexperts, this by no means proves what Mizrahi wants to prove. See footnote 14 for further discussion.

${ }^{12}$ Seidel (2014, p.201) also says that the FBI is not an expert but argues for this on the basis that the FBI are making claims outside of their area of expertise, making it an issue about epistemic trust. Again, Seidel could have saved himself the trouble: it is effectively stipulated that the FBI are non-experts when it is said that their claims are uncorroborated and not backed by source data or methodology. It is an issue about professional trust rather than epistemic trust, which is an afterthought. I wonder whether both Mizrahi and Seidel are misinterpreting though: what it actually says is not that the FBI had no evidence but that it had no record of this evidence, or even more weakly that it did not provide it for the article, and for this reason the FBI's claim could not be corroborated by the publishers of the article.
}

(C) David Botting. Informal Logic, Vol. 38, No. 4 (2018), pp. 502-530. 
tise (i.e., scientific procedures). I think that these examples fail for a quite different reason: they ignore doubt-preservation.

All arguments from position to know must observe what I call doubt-preservation. Mizrahi asks: would you trust a watch that gets the time right $55 \%$ of the time? Well, it depends. I wouldn't trust it to the extent of taking myself to be justified in believing that the time it tells me is the right one, but if I were offered a bet at even odds on what the time is, I would be justified in taking that bet on the basis of what the watch told me. Suppose that the expert does not take herself to be justified to believe that $p$ but only to accept that $p$, or make a best guess that $p$. What goes for the expert goes also for whoever appeals to the expert's opinion, who should not draw a stronger conclusion than the expert. In other words, if $E$ asserts that $p$, or performs some other act indicating that she takes herself to have justified belief that $p$, then the arguer likewise would (other things being equal) be justified in believing that $p$. If, on the other hand, $E$ expresses $p$ tentatively and with reservations, then the arguer likewise would be justified only in holding the opinion to be true in the same tentative manner. It would be an error for the arguer to take himself to be justified in believing outright that $p$ if the expert herself only takes herself justified to hold that $p$ tentatively. Unfortunately, that is the question Mizrahi's examples in group 3 asks: it takes claims that are made only tentatively, and then appears to find it surprising that these turn out not to justify outright belief. The argument from position to know is doubt-preserving: those who are not in a position to know are not justified in holding a proposition to be true more strongly than the person who is in a position to know and to whose opinion the arguer is appealing.

In short, the cognitive attitude that I take to be justified on the basis of the expert opinion matters, and the argument is to be evaluated according to whether it provides strong reasons for that attitude. Economists making forecasts, doctors making diagnoses, scientists making bold claims all know that they may very well turn out to be wrong and make their claims only tentatively. In the examples, in group 3 the experts all make tentative claims. This is 
true of prediction generally. ${ }^{13}$ If we ask whether we are justified in believing that what they tell us is true then the answer is obviously "No," but this is the wrong question. The right question is whether we are justified in having the same cognitive attitude that the expert herself has, and these cases do not show this to be false. ${ }^{14}$ This is what all participants in the debate (including, I think, Walton in setting up the original argumentation scheme) seem to miss.

Are there empirical results about expertise that implies we would not be justified in believing the claims of experts when those experts can be assumed to be acting professionally, following procedures, and are making claims that imply having justified beliefs? Mizrahi points out in (d) that most papers published in medical and economic journals have turned out to be false within a few years, and the same could be said, albeit with a longer time-

\footnotetext{
13 There is a certain vagueness here, for which reason I say that this is true only "generally" and not "always". We tend to think of predictions as only advanced tentatively. Yet, strictly speaking, any claim about the future is a prediction, and some may be held confidently, some only tentatively. With this proviso, predictions ought to be thought of as implying cognitive attitudes weaker than outright belief.

14 This is a completely different kind of objection from that pressed by Seidel and Hinton, who get side-tracked onto the issue of whether experts are better at making certain kinds of predictions than non-experts. Even if experts are not better than non-experts, it still would not follow that an argument from expert opinion would be weak, as I said above; at worst, it would be lazy. But let us assume the more likely case that the experts' predictions are in fact better. The point about doubt-preservation still stands: the non-expert is not justified in having a stronger cognitive attitude than the expert (or, to be more accurate, stronger than the expert expresses in her testimony). While Seidel and Hinton agree with Mizrahi that these arguments are weak, I maintain that they are only weak if you take the cognitive attitude of the arguer to be outright belief rather than tentative belief: outright belief is not justified, tentative belief is, and so the argument from expert opinion is a strong argument (albeit for a weakly held belief). True, this does require some surgery to Walton's argumentation scheme, which only talks about assertion and belief. What I would say is that, interpreted strictly to concern assertion and belief, these examples are simply not instances of these argumentation schemes for the simple reason that the experts are not making assertions, or at least, not assertions of the kind that one would not make without taking oneself to have justified belief in what one is asserting.
}

(C) David Botting. Informal Logic, Vol. 38, No. 4 (2018), pp. 502-530. 
frame, about the exact sciences. This seems to be the most likely place to find an example to Mizrahi's advantage.

The issue here is not whether we ought to call them "experts" who have turned out to be wrong. Thus, Seidel (2014, p. 256) wants to claim that Aristotle was an expert on biology. Perhaps he was: let's not quibble over a word. The issue though is whether we would be justified in believing some biological claim on Aristotle's authority. Perhaps a contemporary of Aristotle would be justified, but it seems equally clear that we would not, given what we know now, irrespective of how advanced Aristotle was for his time. Aristotle is not an expert in the sense required for it to be sensible to appeal to his epistemic authority or expertise on biological matters.

The real issue can be put this way: are we justified now in believing the claims of our best science, given that we know that they may well turn out to be false? Some of these claims may only be believed and advanced tentatively, but some are believed and advanced as outright knowledge-claims. What about these?

Now, an expert can, of course, over-estimate the epistemic force of his evidence and believe his claim more strongly than is really justified by the evidence - scientists can be as guilty of cognitive biases and favouritism towards their own theories as anyone else. If we know that this is true of the specific case, then any appeal to that particular opinion would be weak; again, we do not take the individual to be fully professional in this circumstance. Generally, though, it is not obvious that we should take all such arguments to be weak just on the basis of a possibility. We know that we ourselves are susceptible to such biases, yet do not (unless we are Pyrrhonists) take this as reason not to have any beliefs at all. We are as justified in appealing to an expert's belief as we are in appealing to our own belief - if we were not, we could not be appealed to by others as epistemic authorities on facts we are in a position to know. ${ }^{15}$

\footnotetext{
${ }^{15}$ Mizrahi (2017) goes to some trouble to show that experts are guilty of cognitive biases with the intention of heading off a defence of expertise on the grounds that experts are less prone to cognitive biases than non-experts. As far as this goes, he succeeds. I get the impression, though, that he wants to make the
}

(C) David Botting. Informal Logic, Vol. 38, No. 4 (2018), pp. 502-530. 
Let us assume the expert to be fully professional and set aside all concerns about bias. The problem we are left with is a familiar one from the philosophy of science where it is called the "pessimistic induction." The pessimistic induction asks, "Should we believe the claims of our best science given that, historically, what was our best science in the past has turned out in the present to have been mistaken?" The question "Should we believe the claims published in the most prestigious scientific journals given that, historically, what was published in the past has turned out in the present to have been mistaken?" is only a minor variation of this. By assimilating such published claims with our best, most confirmed and least biased science I mean to exclude all those claims that are made more speculatively and less justifiably.

It is perhaps a little strange then to find Mizrahi arguing against the pessimistic induction in (2013a) and to find him claiming that the induction is based on a biased sample, it being the case that many more theories have been found to be true than have been found to be false. Again, Mizrahi will probably say that it is justified to believe in the claims of our best science on the basis of the evidence and the procedural controls used on that evidence, and not simply because of what the expert says. But this, I have said before, solves the problem more or less by stipulation. Group 3 both does

stronger claim that the fact that experts are guilty of biases itself shows that appeal to expert opinion is weak. It does not show this. If it did, we would be equally unjustified in maintaining our own beliefs, yet we do not seem rationally required to withdraw all belief when we become aware that we might have committed cognitive errors and do not know for a fact that we did not. In other words, I don't think consideration of cognitive biases defends expertise or attacks it.

At the same time, I think this points to a tension in Mizrahi's account, since he allows appeals to experiments and decision procedures to be good, but decision procedures are surely intended, at least in part, to correct for things like cognitive biases. Yet one wonders how it can be true that scientists who follow procedures can still be as guilty of cognitive biases as Mizrahi seems to be saying, and if they are, how come this does not make appeal to those same procedures equally weak? If they did not help the expert to avoid unjustified beliefs, why should they help the non-expert any better? This echoes what I said above about the fragility of Mizrahi's appealing not to experts but to their evidence and procedures.

(C) David Botting. Informal Logic, Vol. 38, No. 4 (2018), pp. 502-530. 
not prove what Mizrahi wants and is arguably inconsistent with what he says about the pessimistic induction.

None of Mizrahi's examples really prove his case. In conclusion, I do not believe that Mizrahi has shown the inductive argument from position to know to be weak. I do think that he has shown it to be not very interesting, in the sense that it reduces to an ordinary inductive argument where ethotic considerations are dispensable: we do not need to suppose that the person in a position to know is not biased and is honest and conscientious. It is curious that Walton, Reed, and Macagno (2008, p.246) actually seem to reach a similar but weaker conclusion with respect to bias when they say: "Even if an expert is biased ... it does not follow that she is not an expert". What they want to show here is that consideration of bias can undercut the inference without attacking the premises. I would go further: it does not follow that she is not (objectively speaking) reliable, and if she is reliable, then the inference is not undercut after all. An affirmative response to the Trustworthiness Question gives the arguer reason to think that the one in a position to know does reliably say true things but being trustworthy is not a necessary condition of being reliable in the sense required for a valid inductive argument from position to know or to give strong reasons.

\section{The non-inductive argument from position to know}

Mizrahi has defined a genuine appeal to expert opinion to be such that the correct answer to "Why should I believe that?" is "Just because I (the expert) said so!" If, in order to justify that answer, further evidence must be provided (e.g., a track record of independently verified truth-tellings), then these, by definition, amount to suppressed premises such that it is not just because I said so, but because I said so and I am verified as being reliable, or something like this. One might now wonder whether there are any arguments from position to know that satisfy this condition, i.e., which give genuine content-independent reasons. I think that there is, and this is what I call the non-inductive argument from position to know.

According to speech-act theory, there are normative conditions of satisfaction that must be satisfied for an utterance to be a particu-

(C) David Botting. Informal Logic, Vol. 38, No. 4 (2018), pp. 502-530. 
lar kind of speech-act and to succeed as this kind of speech-act. Suppose that I say to you the ordinary declarative sentence "The cat is on the mat." In an ordinary context you will take me as attempting to convey to you the information that the cat is on the mat, that is to say, as performing the illocutionary act of asserting, and in order to be performing such an act I must be attempting to convey to you some fact that I sincerely believe to be true. Also, it is normative for you to interpret my utterance as such an attempt, even if you also think that the attempt fails. Note that the truth of what I assert is not necessary for my asserting to be successful since my asserting need only be successful as an attempt to say something true, although truth obviously is necessary for me to succeed at what I am attempting.

Furthermore, in order to produce coherent interpretations of people's utterances - that is to say, in order to communicate at all-we must take their attempts to be successful at least more often than not, and it is normative for us to do so. Therefore, given that you have a normative reason for interpreting my utterance that the cat is on the mat as a successful, though not necessarily truthful, act of asserting that the cat is on the mat, and a normative reason also to believe that most such acts succeed at what the speaker is attempting to do-namely, be truthful-then you have a normative reason to believe that the cat is on the mat, and this for the very reason that I said it. I have epistemic authority. Note that this is not something that you have inferred: it is embedded in the norms of communication itself. Once you have interpreted me as performing a certain act, there is no longer any question about whether those things obtain that are constitutive of that act, as sincere belief is constitutive of the act of asserting. It follows immediately as part of the act of interpreting. ${ }^{16}$

Now, it might be asked whether this normative reason is "the right kind of reason." Generally, the fact that we might be better off in some sense if we are in a particular epistemic state (e.g., of believing $p$ ) than if we are not does not justify our being in that state. In other words, it does not justify our believing $p$ that we

\footnotetext{
16 This is one way of trying to cash out the kind of "common-sense" view with which Thomas Reid countered Hume.
}

(C) David Botting. Informal Logic, Vol. 38, No. 4 (2018), pp. 502-530. 
might be in a better position-whether pragmatically, prudentially, or sometimes even in a better epistemic position - by believing $p$ if in fact we have no evidence for the truth of $p$. We might be putting ourselves in the best position with respect to norms of communication by believing what people say, but does this really justify our believing what people say?

But in this case, other things being equal and provided that you do not have evidence that the speaker is not attempting to say something true, the normative reason is also a justifying reason, at least to some extent. That is to say that your belief that the cat is on the mat, brought about by my asserting that it is so, is justified, and the fact of my saying that it is so is evidence for its being so. This is so simply because most such sayings are of something true. This is not an extra premise, but simply the situation you find yourself in when you attempt to interpret what I say as an attempt at meaningful communication and hope likewise to respond meaningfully. Note that if the cat is not on the mat but I believe that it is, then I am still successfully asserting, and it is still normative for you to interpret me as having successfully asserted. But, if you know that the cat is not on the mat, then there does not seem to be a normative reason for believing that $\mathrm{I}$ have told you something true since you know that I have not done what I was attempting to do, this being one of those cases where other things are not equal. The second part of the argument - the second normative reason-does not go through in this circumstance.

When it comes to epistemic authority, then, normative reasons justify, but one can have justifying reasons, even justifying testimonial reasons, that are not dependent on the source in this way. We have already seen this in the inductive argument. For example, suppose that you discover that most of my declarative sentences express truths, where this is independent of the fact that you have a normative reason for interpreting me as making assertions. Perhaps you have no commitment at all vis-à-vis my truthfulness, or even believe, with good reason, that I am not attempting to be truthful in anything I say. In short, all the critical questions about my trustworthiness are answered in the negative. Even so, the fact that most of the things I say have turned out to be true, despite my intentions 
to deceive, is a justifying reason for you to believe that it is true that the cat is on the mat when I say it and because I say it, but not just because I say it, but because of further facts that you know about the things I say. You are not taking me as an epistemic authority in this situation, and if I make no attempts to be truthful, I do not have any such authority. Here, the argument from position to know is what I have called the inductive argument from position to know, and there is no non-inductive argument from position to know that can be appealed to here. Of course, the situation is peculiar and typically you should and will take me to be an epistemic authority. In this case, I think that you have even more justification since you have the reliability of my testimony plus the contentindependent reason due to my epistemic authority. The contentindependent reason is a separate reason that must be taken into account in the overall weighing of reasons. Here you have both arguments from position to know-the inductive and noninductive - and both provide separate reasons.

\section{Conclusion}

Argumentation schemes for argument from position to know/expert opinion such as Walton's, since they bring in further premises on which the strength of the argument depends, do not give a contentindependent reason. Since I have said that it is characteristic of authorities that they give content-independent reasons, these schemes do not genuinely appeal to authority, but at best their critical questions provide further confirmation that such and such is an authority. For example, if the arguer can answer the Trustworthiness Question in the affirmative, then that is confirmation that the person in a position to know is an epistemic authority. However, it is normative (i.e., in accordance with norms of communication) to take such a person as an epistemic authority even without such confirmation, as long as there is no reason to think that there are not trustworthy and consequently not well interpreted as attempting to be truthful. This is what I have called the non-inductive argument from position to know, and this gives a content-independent reason. 
However, this does not mean that Walton's kind of argumentation scheme does not provide reasons as well when properly supported. Up to this point, I think that defenders of expertise could accept that they are not giving content-independent reasons and claim that Mizrahi has simply talked past them by more or less stipulating that their argumentation scheme is not a genuine argument from authority. Also, it is not clear how an argument from an expert's evidence can be strong while an argument from expert opinion can be weak if we suppose that the expert is being professional and basing his opinion on precisely that evidence that Mizrahi seems to concede may provide strong, belief-justifying reasons. Hence, I think that there are strong instances of argument from position to know and expert opinion as Walton-and probably most others - understand it. However, I don't think they realise how far this kind of argumentation scheme reduces in the end to an appeal to a reliable source, and since the same evidence that would be used to establish trustworthiness establishes reliability too, we can appeal to reliability directly without having to worry about trustworthiness. This is the inductive argument from position to know, and as far as it is concerned, the trustworthiness of the expert plays no role in the evaluation of the strength of the argument. As Mizrahi (2017, p. 11) puts it: "Walton's argumentation scheme for arguments from expert opinion faces a dilemma: if there is evidence for an expert's assertion from a source that is more reliable than expert opinion, why rely on expert opinion at all?"17 Indeed, the expert is just a particular case of a source of information with no significant differences from other kinds of sources as far as the strength of the inductive argument is concerned.

I think that Mizrahi makes a lot of good points, some deliberately, others almost by accident. Moreover, if experts are not reliable, then there simply are no good instantiations of the inductive argument from position to know. Nonetheless, I think that the empirical

\footnotetext{
${ }^{17}$ Mizrahi is talking about the "Backup Evidence Question" (a Critical Question for the argumentation scheme from expert opinion) rather than the "Trustworthiness Question" here, but the moral is the same, since the arguer must have independently verifiable evidence of the expert's trustworthiness. He can hardly take the expert's word for their own trustworthiness!
}

(C) David Botting. Informal Logic, Vol. 38, No. 4 (2018), pp. 502-530. 
evidence he provides that experts are not reliable is inadequate mostly because he (and, to be fair, everyone else) ignores what I called doubt-preservation. For example, if I am going to justify belief that $p$ by appeal to someone in a position to know that $p$, then I must take that person to be expressing their belief that $p$. I must take that person to be uttering an assertion or some other speech-act that implies sincerity, and I must take that person to be observing a Gricean Maxim of Quality so that they would not assert $p$ in a situation where they are going to be taken as authoritative about $p$ without having evidence that $p$ is true. Most of Mizrahi's examples are either of experts making much more tentative claims or not being professional, whereas the kind of examples we are interested in are those where experts make confident claims and are being professional. Are these unreliable? Would it be a weak argument to appeal to their opinion?

Further confusing the issue, Mizrahi presumes that the experts are operating under uncertainty. Again, if they really are uncertain, then this will be reflected in their own cognitive attitudes and consequently in what cognitive attitudes arguers would be justified in having on the basis of what the experts say. But I am not sure what the basis of this presumption is. At (2017, p. 1) Mizrahi says, "An argument from expert opinion is an argument one makes 'under conditions of uncertainty" but here it is the arguer's uncertainty that is at issue and not the expert's. At $(2017$, p. 3) and at $(2016$, p. 246) it is the expert's judgment under uncertainty that is at issue and claimed to be not significantly better than that of a nonexpert. ${ }^{18}$ But why, just because the arguer is uncertain, should we suppose that the expert is not confident and, by virtue of this, provide strong reasons for what he says? There is no reason at all that I can see. Thus, I think that Mizrahi's argument fails: some arguments from position to know are strong. In fact, there are two types

\footnotetext{
${ }^{18}$ It is not without reason that both Seidel (2014) and Hinton (2015) think that Mizrahi is talking specifically about the comparative abilities of experts and nonexperts at making predictions. Mizrahi denies this in (2016). What all seem to fail to realise is that the only cognitive attitude that can be justified on the basis of an expert's prediction is another prediction or bet with favourable odds (or something like this), and not belief.
}

(C) David Botting. Informal Logic, Vol. 38, No. 4 (2018), pp. 502-530. 
of such arguments, and they can be strong or weak almost independently of each other. ${ }^{19}$

\section{Acknowledgments}

Funding for this research was provided by the FCT Portugal under grants PTDC/FIL-FIL/110117/2009 and SFRH/BPD/77687/2011.

\section{References}

Hinton, M. 2015. Mizrahi and Seidel: Experts in confusion. Informal Logic 35(4): 539-554.

Mizrahi, M. 2017. Arguments from expert opinion and persistent bias. Argumentation 32(2): 175-195

Mizrahi, M. 2013a. The pessimistic induction: a bad argument gone too far. Synthese 190(15): 3209-3226

Mizrahi, M. 2016. Why arguments from expert opinion are still weak: A reply to Seidel. Informal Logic 36(2): 238-252.

Mizrahi, M. 2013b. Why arguments from expert opinion are weak arguments. Informal Logic 33(1): 57-79.

Seidel, M. 2016. The real struggle: An objective notion of expertise? Informal Logic 36(2): 253-264.

Seidel, M. 2014. Throwing the baby out with the water: From reasonably scrutinizing authorities to rampant scepticism about expertise. Informal Logic 34(2): 192-218.

19 Almost, but not quite: if the inductive argument is bad, then this will be evidence that the testifier is not trustworthy, and so the non-inductive argument will be bad too. One could not, then, have a good non-inductive argument with a bad inductive argument, but one could however have a good non-inductive argument without an inductive argument at all (because unable to provide evidence in response to critical questions). This becomes crucial when we start to consider testimony about things that cannot be empirically verified. Suppose that an expert on theology makes some theological claims. According to the inductive way of doing things, we need to be able to establish their reliability, which means that we need to establish independently whether at least some of that expert's testimony is true. But it is not obvious how we can do this, given the unverifiability of such claims. However, a non-inductive argument may still be viable in this situation.

(C) David Botting. Informal Logic, Vol. 38, No. 4 (2018), pp. 502-530. 
Walton, D., Chris Reed and Fabrizio Macagno. 2008. Argumentation schemes. New York: Cambridge University Press

Walton, D. 2014. On a razor's edge: evaluating arguments from expert opinion. Argument \& Computation 5: 139-159.

(C) David Botting. Informal Logic, Vol. 38, No. 4 (2018), pp. 502-530. 